\title{
Evaluation of serum lipid, lipoprotein, and apolipoprotein levels in psoriatic patients: a systematic review and meta-analysis of case-control studies
}

\author{
Mazaher Ramezani', Elisa Zavattaro², Masoud Sadeghi³,4 \\ ${ }^{1}$ Molecular Pathology Research Centre, Imam Reza Hospital, Kermanshah University of Medical Sciences, Kermanshah, Iran \\ ¿Dermatology Unit, Department of Translational Medicine, University of Eastern Piedmont “Amedeo Avogadro”, Novara, Italy \\ ${ }^{3}$ Medical Biology Research Centre, Kermanshah University of Medical Sciences, Kermanshah, Iran \\ ${ }^{4}$ Students Research Committee, Kermanshah University of Medical Sciences, Kermanshah, Iran
}

Adv Dermatol Allergol 2019; XXXVI (6): 692-702

DOI: https://doi.org/10.5114/ada.2019.91420

\begin{abstract}
Introduction: Psoriasis is a T cell-mediated inflammatory skin disease in which fatty acids may be a link between psoriasis and its comorbidity.

Aim: The present meta-analysis aimed to evaluate lipid, lipoprotein, and apolipoprotein levels in the psoriatic patients compared with the control subjects.

Material and methods: Four databases, including Web of Science, Scopus, PubMed, and Cochrane Library were searched until July 2017. All records analysed were case-control studies. The quality of the questionnaires was evaluated using the Newcastle-Ottawa Scale (NOS). A random-effects meta-analysis was done by Rev Man 5.3 using mean difference (MD) and 95\% confidence intervals (Cls).

Results: Out of 580 studies identified in four databases, 49 studies were included and analysed in this metaanalysis. The results showed that MD of total cholesterol, triglyceride, LDL, VLDL, HDL, Lp(a), Apo A1, and Apo $B$ levels in the patients compared with the controls were $(\mathrm{MD}=13.74 \mathrm{mg} / \mathrm{dl} ; 95 \% \mathrm{Cl}: 7.72-19.75 ; p<0.00001)$, $(\mathrm{MD}=26.04 \mathrm{mg} / \mathrm{dl} ; 95 \% \mathrm{Cl}: 20.77-31.31 ; p<0.00001),(\mathrm{MD}=11.41 \mathrm{mg} / \mathrm{dl} ; 95 \% \mathrm{Cl}: 6.26-16.57 ; p<0.0001)$, $(\mathrm{MD}=4.82 \mathrm{mg} / \mathrm{dl} ; 95 \% \mathrm{Cl}: 3.63-6.00 ; p<0.00001),(\mathrm{MD}=-2.78 \mathrm{mg} / \mathrm{dl} ; 95 \% \mathrm{Cl}:-4.53--1.03 ; p<0.002),(\mathrm{MD}=8.51$ $\mathrm{mg} / \mathrm{dl} ; 95 \% \mathrm{Cl}: 4.86-12.17 ; p<0.0001),(\mathrm{MD}=-6.60 \mathrm{mg} / \mathrm{dl} ; 95 \% \mathrm{Cl}:-13.96-0.75 ; p<0.08)$, and (MD = $9.70 \mathrm{mg} / \mathrm{dl}$; 95\% Cl: 3.02-16.39; $p<0.004)$, respectively.

Conclusions: This meta-analysis identified abnormality of serum lipid, lipoprotein, and apolipoprotein profiles in psoriatic patients compared with the controls as well as possibly a greater risk of atherosclerosis and cardiovascular (CV) accidents in the patients.
\end{abstract}

Key words: psoriasis, serum, lipid, lipoprotein, apolipoprotein.

\section{Introduction}

Psoriasis is one of the most common T cell-mediated inflammatory skin diseases with an unknown aetiology and a prevalence of about $1-3 \%$ in the general population [1-3]. Psoriasis can be caused by the combined effects of genetic and environmental factors on the immune system [4]. The disease is associated with abnormal plasma lipid metabolism and oxidative stress [3]. Psoriasis is accompanied by metabolic disturbances and cardio-metabolic disorders, and fatty acids may be a link between psoriasis and its comorbidity [5]. Inflammatory activity in psoriasis acts independently as a cardiovascular (CV) risk factor [6]. In psoriatic patients, lipid abnormalities are correlated with increased mortality due to myocardial infarction and stroke [7]. Psoriasis area and severity index (PASI) score is used to grade the cases into mild, moderate, and severe. This score is considered outstanding when severe cases are involved. It also provides an advantage for a large base of studies in which it has been used for comparison [8]. The severity of psoriasis is correlated with body mass index (BMI), especially with abdominal fat, which represents the source of production of a complex network of adipokines [2]. Plasma lipopro-

Address for correspondence: Masoud Sadeghi MSc, Medical Biology Research Centre, Kermanshah University of Medical Sciences, 67145-1673 Kermanshah, Iran, phone: + 98 9185960644, e-mail: sadeghi_mbrc@yahoo.com Received: 12.06 .2018 , accepted: 11.07.2018. 
teins, besides their important role in the bulk transport of lipids, are also involved in maintaining a proper lipid composition of cell membranes [9]. The plasma concentration of the major apoprotein of low-density lipoprotein $(\mathrm{LDL})$, apolipoprotein B (Apo B), is frequently increased in patients with coronary disease, while apolipoprotein A1 (Apo A1), the major protein component of high-density lipoprotein ( $\mathrm{HDL}$ ) is an antiatherogenic factor [10]. Apo B transports all potentially atherogenic very low-density lipoprotein (VLDL), intermediate-density lipoprotein, and LDL particles [11].

\section{Aim}

The aim of the present meta-analysis was the evaluation of lipid, lipoprotein, and apolipoprotein levels in the psoriatic patients compared with the control subjects.

\section{Material and methods}

This meta-analysis was designed based on the guidelines for the preferred reporting items of the systematic review and meta-analysis (PRISMA statement) [12].

\section{Search strategies}

Four databases, including Web of Science, Scopus, PubMed, and Cochrane Library were searched for evaluation of serum lipid, lipoprotein, and apolipoprotein levels in psoriatic patients using the search terms "lipid or lipoprotein or apolipoprotein", "psoriasis", and "serum". The search was done for publications until July 2017.

\section{Study selection}

The studies were searched for assessment of serum lipid, lipoprotein and apolipoprotein profiles of psoriatic patients compared with the healthy controls in English abstracts. Studies were included if they were case-control ones with two groups (psoriatic patients and healthy controls), they evaluated the serum profile, including the mean/median lipid or lipoprotein levels, the healthy controls did not have any systemic or other relevant skin diseases, and the patients had just psoriasis; studies including patients with psoriatic arthritis were excluded. Reviews, letters to editor or case reports, and studies not having full-text, not reporting mean or median of serum levels, or having no relevant data were excluded from the analysis. The exclusion criteria in most studies for the psoriatic patients and controls included concomitant diseases potentially disturbing lipid metabolism (i.e. CV, hypertension, diabetes mellitus (DM), thyroid gland disorders, nephrotic syndrome, chronic kidney failure, and obstructive liver disease), any systemic medication known to affect lipid metabolism or evaluate immunological parameters for a specified period and studies including patients with a recent history of infections.

\section{Data extraction from studies}

Three authors did the process of data extraction. The first author (M.S.) searched the studies and screened titles and abstracts of every study based on the abovementioned criteria and extracted data. The second author (M.R.) independently re-checked the full texts of screened studies. Data collected for every study included the first author, year of publication, journal, country, sample size of patients and controls, percentage of male patients and controls, mean age of patients and controls, $\mathrm{BMI}$ of patients and controls, mean PASI of patients, serum total cholesterol, triglyceride (TG), LDL, HDL, VLDL, lipoprotein a (Lp(a)), Apo A1, and Apo B levels of patients and controls. Lipid and lipoprotein levels were measured by the standard enzymatic method in most studies and mean values were expressed in $\mathrm{mg} / \mathrm{dl}$. The third author (E.Z.) resolved the disagreement between the two previous authors.

\section{Quality evaluation}

The quality of the questionnaires was evaluated using the Newcastle-Ottawa Scale (NOS) with a total score of nine for every study, 7-9 as high quality, 4-6 as medium quality, and 0-3 as low quality [13]. The quality of every study was evaluated by two authors (M.R. \& M.S.) by reaching a consensus via discussion. Therefore, a study with a score $\geq 7$ was found to have a high quality.

\section{Statistical analysis}

A random-effects meta-analysis was done by Review Manager 5.3 (Rev Man 5.3, The Cochrane Collaboration, Oxford, United Kingdom) using mean difference (MD) and $95 \%$ confidence intervals ( $\mathrm{Cls}$ ). The $Q$ and $P$ statistics were used to assess heterogeneity between the estimates. For the $Q$ statistic, heterogeneity was considered if $p<0.1$, and $p$-value $(2$-sided $)<0.05$ was considered statistically significant in other analyses. In addition, publication bias was assessed through funnel plot analysis along with Begg's and Egger's tests. We used a formula for estimation of mean and SD if the study reported median plus range and for estimation of SD if the study reported standard error (SE) [14, 15]. The units of serum lipid and lipoprotein levels were $\mathrm{mg} / \mathrm{dl}$. In a number of studies, the VLDL level was estimated by the formula $\mathrm{VLDL}=$ triglyceride/5.

\section{Results}

\section{Literature search}

Out of 580 studies identified in four databases, after removing the duplicate ones, 362 studies were screened (Figure 1). Among these, 288 studies were excluded be- 


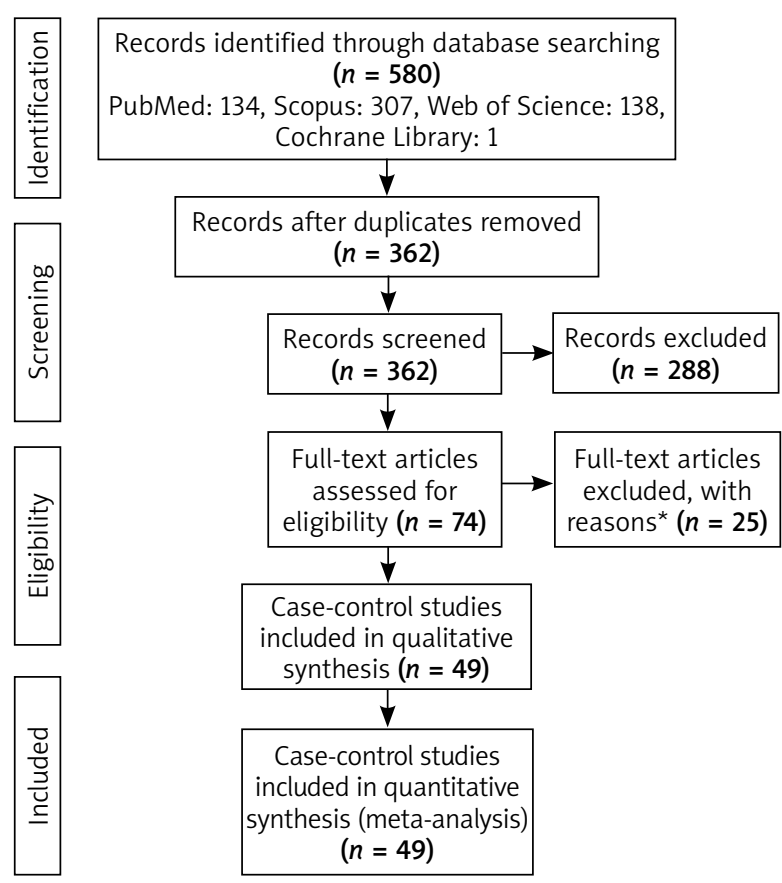

*2 studies reported child patients; 11 studies didn't have control group or didn't report variables in control group; 1 study reported lipids' receptors; 1 study was review, 1 study reported mean difference; 7 studies reported percentage of variables; 1 study was clinical trial; 1 study separated psoriasis patients (with or without metabolic syndrome).

Figure 1. Flow-chart of the study

cause they were not relevant, and 74 studies were evaluated for eligibility. At last, 25 other studies were excluded for reasons reported in Figure 1, so a total number of 49 studies were included and analysed in meta-analysis.

The studies were published between 1989 and 2017. The meta-analysis included 2600 psoriatic patients and 2358 healthy controls. The mean age of patients was 40.89 years (range: 26.03-49.70 years) and that of healthy controls 39.64 years (range: $23.40-49.48$ years). Thirteen studies were reported from Turkey [16-28], eight from Iran [11, 29-35], seven from India [36-42], five from Poland [5, 43-46], three from the USA [47-49], two from Spain [2, 10], Japan [50, 51], Egypt $[52,53]$, and Italy [54, 55], one from Austria [56], Romania [1], Portugal [57], Iraq [58], and China [59]. Three studies [5, 47, 56] reported the median and one study [57] reported SE, which were converted to mean and SD, respectively. A full description of the examined studies can be found in Supplementary Table S1 and Supplementary Figure S1.

\section{Lipid and lipoprotein profiles}

The pooled analysis showed that MD of studies reporting serum total cholesterol levels in psoriatic patients compared with healthy controls was $13.74 \mathrm{mg} / \mathrm{dl}$ (95\% Cl: 7.72-19.75; $p<0.00001$ ), with heterogeneity of 90\% (Figure 2). The results showed that the mean total cholesterol level was significantly higher in the patients than the controls.
The pooled MD for comparison of serum TG levels in the psoriatic patients compared with the controls was $26.04 \mathrm{mg} / \mathrm{dl}$ (95\% Cl: 20.77-31.31; $p<0.00001)$, with heterogeneity of $74 \%$ (Figure 3 ). The result showed that the triglyceride level in the patients was significantly higher than in the controls.

Figure 4 shows the mean levels of LDL in the patients compared with the controls. The pooled MD was 11.41 $\mathrm{mg} / \mathrm{dl}$ (95\% Cl: 6.26-16.57; $p<0.0001$ ) with heterogeneity of $89 \%$. Therefore, the LDL level was significantly higher in the patients than in the controls.

A random-effects meta-analysis of serum VLDL levels in the psoriatic patients compared with the controls is shown in Figure 5. The pooled MD was $4.82 \mathrm{mg} / \mathrm{dl}$ (95\% Cl: 3.63-6.00; $p<0.00001$ ) with heterogeneity of $77 \%$. The level of this lipoprotein was significantly higher in the patients than in the controls.

The results of serum HDL levels in the psoriatic patients compared with the controls are reported in Figure 6. The pooled MD was $-2.78 \mathrm{mg} / \mathrm{dl}(95 \% \mathrm{Cl}$ : $-4.53--1.03$; $p<0.002$ ). The level of this lipoprotein was significantly lower in the patients than in the controls (heterogeneity $=91 \%$ ).

\section{Apolipoprotein profiles}

The studies reporting $L p(a)$ levels in the patients compared with controls showed that the pooled MD was $8.51 \mathrm{mg} / \mathrm{dl}$ (95\% Cl: 4.86-12.17; $p<0.0001)$, indicating that serum $\operatorname{Lp}(\mathrm{a})$ was significantly higher in the patients than in the controls (heterogeneity $=78 \%$ ), (Figure $7 \mathrm{~A}$ ). Figures $7 B$ and $C$ show the results of $A$ po $A 1$ and $A p o B$, respectively. The pooled MD of Apo A1 was $-6.60 \mathrm{mg} / \mathrm{dl}$ $(95 \% \mathrm{Cl}:-13.96-0.75 ; p<0.08)$ and that of Apo B was $9.70 \mathrm{mg} / \mathrm{dl}$ (95\% Cl: 3.02-16.39; $p<0.004)$, and heterogeneities were $89 \%$ and $69 \%$, respectively. Therefore, there was no significant difference between the patients and the controls in Apo A1, but Apo B level was significantly higher in the patients than in the controls.

\section{Quality evaluation}

Supplementary Table S2 shows the quality score for studies included in meta-analysis; indicating the mean quality score of 6.1 (medium quality). Nineteen studies had high quality (score $\geq 7$ ).

\section{Publication bias}

Supplementary Figure S2 shows the funnel plot of studies included in each analysis. Begg's and Egger's tests did not reveal significant evidence of publication bias among the included studies in each subgroup.

\section{Discussion}

This extensive meta-analysis evaluated the lipid and lipoprotein levels in psoriatic patients compared with healthy controls. The results showed that total cholester- 


\begin{tabular}{|c|c|c|c|c|c|c|c|c|c|c|c|}
\hline $\begin{array}{l}\text { Study } \\
\text { or subgroup }\end{array}$ & \multicolumn{3}{|c|}{ Psoriasis } & \multicolumn{3}{|c|}{ Control } & $\begin{array}{c}\text { Weight } \\
\text { (\%) }\end{array}$ & $\begin{array}{r}\text { Mean difference } \\
\text { IV, random, } 95 \% \mathrm{Cl}\end{array}$ & \multicolumn{2}{|c|}{$\begin{array}{l}\text { Mean difference } \\
\mathrm{IV} \text {, random, } 95 \% \mathrm{Cl}\end{array}$} & \\
\hline Akhyani, 2007 & 174.88 & 39.83 & 50 & 158 & 31.86 & 50 & 2.3 & $16.88(2.74,31.02)$ & & & \\
\hline Alatas, 2016 & 214.56 & 34.77 & 30 & 201.8 & 35.22 & 30 & 2.2 & $12.76(-4.95,30.47)$ & & & \\
\hline Aldhalimi, 2010 & 216.4 & 20.16 & 50 & 208.8 & 22.09 & 50 & 2.5 & $7.60(-0.69,15.89)$ & & - & \\
\hline Antonucci, 2014 & 231.02 & 36.043 & 40 & 217 & 30.964 & 40 & 2.3 & $14.02(-0.71,28.75)$ & & & \\
\hline Asefi, 2012 & 167 & 42 & 100 & 156.7 & 31.1 & 100 & 2.5 & $10.30(0.06,20.54)$ & & & \\
\hline Azizzadeh, 2010 & 186.31 & 32.77 & 52 & 154.28 & 27.44 & 50 & 2.4 & $32.03(20.32,43.74)$ & & & \\
\hline Bajaj, 2009 & 215.06 & 19.75 & 79 & 179.44 & 18.4 & 79 & 2.6 & $35.62(29.67,41.57)$ & & $=$ & \\
\hline Bilgic, 2015 & 182.18 & 41.51 & 40 & 154.2 & 27.39 & 40 & 2.3 & $27.98(12.57,43.39)$ & & & \\
\hline Cao, 2013 & 196.3 & 45.4 & 100 & 189.1 & 44.6 & 53 & $2.3 \%$ & $7.20(-7.75,22.15)$ & & & \\
\hline Coban, 2016 & 194.43 & 43.65 & 35 & 176.44 & 36.22 & 50 & 2.2 & $17.99(0.39,35.59)$ & & & \\
\hline El-Hadidi, 2014 & 184.23 & 41.04 & 30 & 150.05 & 21.56 & 30 & 2.2 & $34.18(17.59,50.77)$ & & & \\
\hline Emre, 2013 & 177.68 & 33.87 & 54 & 180.45 & 37.33 & 46 & 2.3 & $-2.77(-16.84,11.30)$ & & - & \\
\hline Farshchian, 2007 & 165.66 & 30.08 & 30 & 171.7 & 32.22 & 30 & 2.3 & $-6.04(-21.81,9.73)$ & & 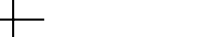 & \\
\hline Farshchian, 2015 & 184 & 47.1 & 55 & 165 & 38 & 55 & 2.2 & $19.00(3.01,34.99)$ & & & \\
\hline Ferretti, 2012 & 193.4 & 40.6 & 25 & 189.1 & 41.4 & 25 & 1.9 & $4.30(-18.43,27.03)$ & & & \\
\hline Holzer, 2014 & 194.32 & 45.75 & 15 & 199.22 & 42.85 & 15 & 1.5 & $-4.90(-36.62,26.82)$ & & & \\
\hline Irimle, 2015 & 163.21 & 56.72 & 142 & 109.47 & 45.29 & 167 & 2.4 & $53.74(42.15,65.33)$ & & & \\
\hline Mehta, 2012 & 189.33 & 40 & 122 & 209.5 & 31.11 & 134 & 2.5 & $-20.17(-29.01,-11.33)$ & & & \\
\hline Mysliwiec, 2017 & 177 & 31.11 & 85 & 174.66 & 29.62 & 32 & 2.4 & $2.34(-9.87,14.55)$ & & & \\
\hline Naik, 2015 & 187.1 & 35.1 & 60 & 184.1 & 35 & 20 & 2.2 & $3.00(-14.72,20.72)$ & & & \\
\hline Nakhwa, 2014 & 189.29 & 36.9 & 100 & 170.79 & 36.25 & 73 & 2.5 & $18.50(7.48,29.52)$ & & & \\
\hline Nemati, 2013 & 123.4 & 67.2 & 90 & 113.3 & 44.3 & 90 & 2.2 & $10.10(-6.53,26.73)$ & & & \\
\hline Okan, 2016 & 165.88 & 48.5 & 45 & 155.11 & 60.75 & 45 & 1.9 & $10.77(-11.94,33.48)$ & & & \\
\hline Pang, 2015 & 162.16 & 35.9 & 86 & 176.44 & 20.46 & 84 & 2.5 & $-14.28(-23.04,-5.52)$ & $\longrightarrow$ & & \\
\hline Pereira, 2011 & 186.27 & 43.18 & 77 & 194.38 & 57.2 & 92 & 2.3 & $-8.11(-23.26,7.04)$ & & & \\
\hline Pietrzak, 2002 & 176.94 & 12.89 & 41 & 182.49 & 11.19 & 57 & 2.6 & $-5.55(-10.45,-0.65)$ & & & \\
\hline Pietrzak, 2006 & 179.25 & 32.79 & 22 & 182.03 & 23.82 & 12 & 2.1 & $-2.78(-22.00,16.44)$ & & & \\
\hline Pietrzak, 2009 & 207.88 & 48.61 & 34 & 209.14 & 31.77 & 26 & 2.0 & $-1.26(-21.66,19.14)$ & & & \\
\hline Piskin, 2003 & 198.9 & 42.15 & 100 & 164.1 & 43.97 & 100 & 2.4 & $34.80(22.86,46.74)$ & & & \\
\hline Prathibha, 2015 & 212.9 & 33.5 & 30 & 189.67 & 26.72 & 30 & 2.3 & $23.23(7.90,38.56)$ & & & \\
\hline Rocha-Pereira, 2001 & 220.4 & 43.7 & 48 & 199.8 & 27.7 & 40 & 2.3 & $20.60(5.55,35.65)$ & & & \\
\hline Seckin, 1994 & 189 & 46.63 & 32 & 191.92 & 57.65 & 13 & 1.4 & $-2.92(-38.18,32.34)$ & & & \\
\hline Seishima, 1994 & 200 & 29 & 38 & 190 & 38 & 40 & 2.3 & $10.00(-4.96,24.96)$ & & & \\
\hline Sereflican, 2017 & 181.59 & 38.63 & 32 & 169.23 & 30.96 & 22 & 2.1 & $12.36(-6.25,30.97)$ & & & \\
\hline Solak, 2017 & 197.9 & 37.5 & 70 & 193.6 & 41.1 & 60 & 2.4 & $4.30(-9.31,17.91)$ & & & \\
\hline Sunitha, 2015 & 160.38 & 36.23 & 45 & 145.33 & 23.53 & 45 & 2.4 & $15.05(2.43,27.67)$ & & & \\
\hline Swelam, 2010 & 220.7667 & 27.8056 & 30 & 175.6 & 11.5469 & 10 & $2.4 \%$ & $45.17(32.91,57.42)$ & & 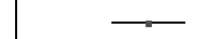 & \\
\hline Taheri Sarvtin, 2014 & 198.2 & 18.81 & 50 & 155.96 & 21.53 & 50 & 2.6 & $42.24(34.32,50.16)$ & & 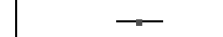 & \\
\hline Takeda, 2001 & 211.74 & 36.32 & 27 & 182.6 & 13.36 & 15 & 2.3 & $29.14(13.86,44.42)$ & & & \\
\hline Toker, 2009 & 171.7 & 41.2 & 30 & 178.1 & 31.6 & 23 & 2.1 & $-6.40(-26.00,13.20)$ & & & \\
\hline Uczniak, 2016 & 145.68 & 29.95 & 246 & 110.92 & 28.83 & 75 & 2.6 & $34.76(27.24,42.28)$ & & & \\
\hline Usta, 2011 & 189.52 & 42.24 & 52 & 177.2 & 30.4 & 25 & $2.2 \%$ & $12.32(-4.23,28.87)$ & & & \\
\hline Uyanik, 2002 & 161.19 & 43.16 & 72 & 145.55 & 31.62 & 30 & $2.3 \%$ & $15.64(0.56,30.72)$ & & & \\
\hline Vanizor Kural, 2003 & 200.386 & 41.31 & 30 & 182.23 & 26.64 & 30 & 2.2 & $18.16(0.57,35.75)$ & & & \\
\hline Total $(95 \% \mathrm{Cl})$ & & 2621 & & & & 2183 & 100.0 & $13.74(7.72,19.75)$ & & & \\
\hline Heterogeneity: $\tau^{2}=$ & $=352.67 ; \chi$ & $x^{2}=437.5$ & $51, \mathrm{~d} f=$ & 4 & 00001 & $=90 \%$ & & & & 50 & 100 \\
\hline Test for overall ef & & & 0 & & & & & & & avours & \\
\hline
\end{tabular}

Figure 2. Forest plot of random-effects model of serum total cholesterol levels in psoriatic patients compared with healthy controls

ol, TG, LDL, VLDL, Lp(a) and Apo B levels were significantly higher in patients, the HDL level was significantly lower in patients than controls, and the Apo A1 level was similar in two groups. It is still controversial whether changes in lipid composition are primary events or secondary to psoriasis, or perhaps due to medications such as cyclosporin and retinoids $[16,50]$. It is also still debated if activation of the immune system in psoriasis may cause some changes in patients' lipid profile, hence in this category of subjects an acceleration of atherosclerosis processes in comparison with the general population has been shown [30, 33, 54]. Additionally, psoriatic patients can be at increased $C V$ risk, even after group matching on the basis of BMI $[43,48,57]$. Apo A1 has been advocated as a strong predictor of CV events, with potential advantages over HDL [33]. 


\begin{tabular}{|c|c|c|c|c|c|c|c|c|c|c|}
\hline \multirow{3}{*}{$\begin{array}{l}\text { Study } \\
\text { or subgroup } \\
\text { Akhyani, } 2007\end{array}$} & \multicolumn{3}{|c|}{ Psoriasis } & \multicolumn{3}{|c|}{ Control } & \multirow{2}{*}{$\begin{array}{c}\text { Weight } \\
(\%)\end{array}$} & \multirow{2}{*}{$\begin{array}{l}\text { Mean difference } \\
\text { IV, random, } 95 \% \mathrm{Cl}\end{array}$} & \multirow{2}{*}{\multicolumn{2}{|c|}{$\begin{array}{l}\text { Mean difference } \\
\mathrm{IV} \text {, random, } 95 \% \mathrm{Cl}\end{array}$}} \\
\hline & Mean & SD & Total & Mean & SD & Total & & & & \\
\hline & 140.3 & 55.24 & 50 & 115.84 & 47.28 & 50 & 2.4 & $24.46(4.31,44.61)$ & & \\
\hline Alatas, 2016 & 181.5 & 79.45 & 30 & 146.43 & 49.02 & 30 & 1.5 & $35.07(1.66,68.48)$ & & \\
\hline Aldhalimi, 2010 & 172.6 & 14.34 & 50 & 139.7 & 13.93 & 50 & 3.5 & $32.90(27.36,38.44)$ & & - \\
\hline Antonucci, 2014 & 158.18 & 53.43 & 40 & 140.22 & 49.193 & 40 & 2.2 & $17.96(-4.55,40.47)$ & & \\
\hline Asefi, 2012 & 123 & 67 & 100 & 113.3 & 44.3 & 100 & 2.7 & $9.70(-6.04,25.44)$ & & \\
\hline Azizzadeh, 2010 & 138.9 & 47.78 & 52 & 102.45 & 35.29 & 50 & 2.7 & $36.45(20.19,52.71)$ & & \\
\hline Bajaj, 2009 & 175.91 & 46.55 & 79 & 147.12 & 38.61 & 79 & 2.9 & $28.79(15.45,42.13)$ & & \\
\hline Bilgic, 2015 & 120.75 & 144.17 & 40 & 90.23 & 36.38 & 40 & 1.0 & $30.52(-15.56,76.60)$ & & \\
\hline Cao, 2013 & 125.4 & 82.8 & 100 & 121.5 & 109 & 53 & 1.5 & $3.90(-29.63,37.43)$ & & \\
\hline Coban, 2016 & 134.83 & 62.46 & 35 & 136.74 & 137.3 & 50 & 1.1 & $-1.91(-45.23,41.41)$ & & \\
\hline El-Hadidi, 2014 & 156.48 & 101.3 & 30 & 70.38 & 13.18 & 30 & 1.3 & $86.10(49.55,122.65)$ & & \\
\hline Emre, 2013 & 132.54 & 76 & 54 & 105.85 & 52.09 & 46 & 2.0 & $26.69(1.44,51.94)$ & & \\
\hline Farshchian, 2007 & 121.63 & 54.56 & 30 & 127.03 & 65.39 & 30 & 1.6 & $-5.40(-35.87,25.07)$ & & \\
\hline Farshchian, 2015 & 152.6 & 72 & 55 & 107.05 & 35 & 55 & 2.3 & $45.55(24.39,66.71)$ & & \\
\hline Ferretti, 2012 & 137.4 & 56.2 & 25 & 87.3 & 21.7 & 25 & 2.1 & $50.10(26.48,73.72)$ & & \\
\hline Girisha, 2017 & 138.49 & 38.98 & 156 & 129.78 & 31.26 & 156 & 3.3 & $8.71(0.87,16.55)$ & & - \\
\hline Holzer, 2014 & 138.58 & 85.13 & 15 & 129.73 & 84.96 & 15 & 0.6 & $8.85(-52.01,69.71)$ & & \\
\hline Irimle, 2015 & 163.21 & 56.72 & 142 & 109.47 & 45.29 & 167 & 3.1 & $53.74(42.15,65.33)$ & & \\
\hline Malelead, 2011 & 146.93 & 59.99 & 30 & 112.2 & 44.73 & 30 & 1.9 & $34.73(7.95,61.51)$ & & \\
\hline Mehta, 2012 & 131.66 & 82.96 & 122 & 126.66 & 50.37 & 134 & 2.6 & $5.00(-12.01,22.01)$ & & \\
\hline Mysliwiec, 2017 & 112.33 & 51.85 & 85 & 113.33 & 52.59 & 32 & 2.3 & $-1.00(-22.30,20.30)$ & & \\
\hline Naik, 2015 & 109 & 38.89 & 60 & 117.17 & 92.96 & 20 & 1.1 & $-8.17(-50.08,33.74)$ & & \\
\hline Nakhwa, 2014 & 219.68 & 101.1 & 100 & 141.31 & 57.9 & 73 & 2.1 & $78.37(54.52,102.22)$ & & \\
\hline Nemati, 2013 & 123.4 & 67.2 & 90 & 113.3 & 44.3 & 90 & 2.7 & $10.10(-6.53,26.73)$ & & \\
\hline Okan, 2016 & 119.18 & 94.25 & 45 & 97.27 & 93.5 & 45 & 1.2 & $21.91(-16.88,60.70)$ & & \\
\hline Pang, 2015 & 118.58 & 60.18 & 86 & 100.88 & 32.74 & 84 & 2.8 & $17.70(3.18,32.22)$ & & \\
\hline Pereira, 2011 & 129.99 & 61.32 & 77 & 141.04 & 80.1 & 92 & 2.3 & $-11.05(-32.39,10.29)$ & & \\
\hline Pietrzak, 2002 & 130.39 & 33.6 & 41 & 107.14 & 34.08 & 57 & 2.9 & $23.25(9.68,36.82)$ & & \\
\hline Pietrzak, 2006 & 111.93 & 37.92 & 22 & 75.6 & 34.94 & 12 & 2.0 & $36.33(10.99,61.67)$ & & \\
\hline Piskin, 2003 & 130.68 & 67.59 & 100 & 111.65 & 47.38 & 100 & 2.7 & $19.03(2.85,35.21)$ & & \\
\hline Prathibha, 2015 & 145.67 & 30 & 30 & 124 & 26.52 & 30 & 2.9 & $21.67(7.34,36.00)$ & & \\
\hline Praveenkumar, 2016 & 149.81 & 24.31 & 30 & 120.93 & 23.81 & 30 & 3.0 & $28.88(16.70,41.06)$ & & \\
\hline Rocha-Pereira, 2001 & 121 & 49.3 & 48 & 92.5 & 27.3 & 40 & 2.7 & $28.50(12.19,44.81)$ & & \\
\hline Romani, 2012 & 125.1 & 72.2 & 50 & 108 & 78.8 & 40 & 1.6 & $17.10(-14.47,48.67)$ & & \\
\hline Seckin, 1994 & 173.84 & 70.46 & 32 & 200.84 & 198.53 & 13 & $0.2-$ & $-27.00(-137.65,83.65)$ & & \\
\hline Seishima, 1994 & 160 & 100 & 38 & 95 & 47 & 40 & 1.4 & $65.00(30.03,99.97)$ & & \\
\hline Sereflican, 2017 & 156.25 & 77.25 & 32 & 136 & 65.25 & 22 & 1.2 & $20.25(-17.96,58.46)$ & & \\
\hline Solak, 2017 & 137.4 & 66.1 & 70 & 138.5 & 93.1 & 60 & 1.8 & $-1.10(-29.29,27.09)$ & & \\
\hline Sunitha, 2015 & 125.56 & 46.13 & 45 & 115.8 & 24.94 & 45 & 2.8 & $9.76(-5.56,25.08)$ & & \\
\hline Swelam, 2010 & 194.96 & 28.67 & 30 & 144.1 & 16.62 & 10 & 2.8 & $50.86(36.32,65.40)$ & & \\
\hline Taheri Sarvtin, 2014 & 156.32 & 56.15 & 50 & 117.06 & 81.41 & 50 & 1.8 & $39.26(11.85,66.67)$ & & \\
\hline Takeda, 2001 & 103.85 & 36.47 & 27 & 81 & 28.11 & 15 & 2.4 & $22.85(3.06,42.64)$ & & \\
\hline Toker, 2009 & 114.2 & 61 & 30 & 144.9 & 98.6 & 23 & 1.0 & $-30.70(-76.53,15.13)$ & & \\
\hline Uczniak, 2016 & 145.68 & 29.95 & 246 & 110.92 & 28.83 & 75 & 3.4 & $34.76(27.24,42.28)$ & & 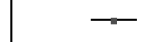 \\
\hline Usta, 2011 & 138.69 & 66.33 & 52 & 88.33 & 51.11 & 25 & 1.9 & $50.36(23.41,77.31)$ & & \\
\hline Uyanik, 2002 & 150 & 25.84 & 72 & 114.96 & 21.77 & 30 & 3.2 & $35.04(25.23,44.85)$ & & \\
\hline Vanizor Kural, 2003 & 3146.02 & 61.06 & 30 & 100.88 & 46.9 & 30 & 1.8 & $45.14(17.59,72.69)$ & & \\
\hline Total $(95 \% \mathrm{Cl})$ & & & 2853 & & & 2413 & 100.0 & $26.04(20.77,31.31)$ & & \\
\hline $\begin{array}{l}\text { Heterogeneity: } \tau^{2}= \\
\text { Test for overall effec }\end{array}$ & 200.1 & $l^{2}=$ & 14 & $=4 c$ & U. & & & & $\begin{array}{c}-50 \\
\text { Favours (psoriasis) }\end{array}$ & Fave \\
\hline
\end{tabular}

$S D$-standard deviation. *Study or subgroup shows "the first author's name and publication year".

Figure 3. Forest plot of random-effects model of serum triglyceride (TG) levels in psoriatic patients compared with healthy controls

Apo A1 has protective effects against CV disease, whereas Apo B increases the CV risk [11]. Some evidence showed that Apo B might be a better predictor for CV disease than LDL [3]. The carriers of PON1 M allele have distinctly reduced ApoA1 levels, but have increased Lp(a) and Apo B levels. These findings indicate that this polymorphism may be involved in the development of atherosclerosis and cardiovascular diseases (CVD) in patients with psoriasis. In general terms, a strict relationship between psoriasis, lipoproteins and oxidative damage does 


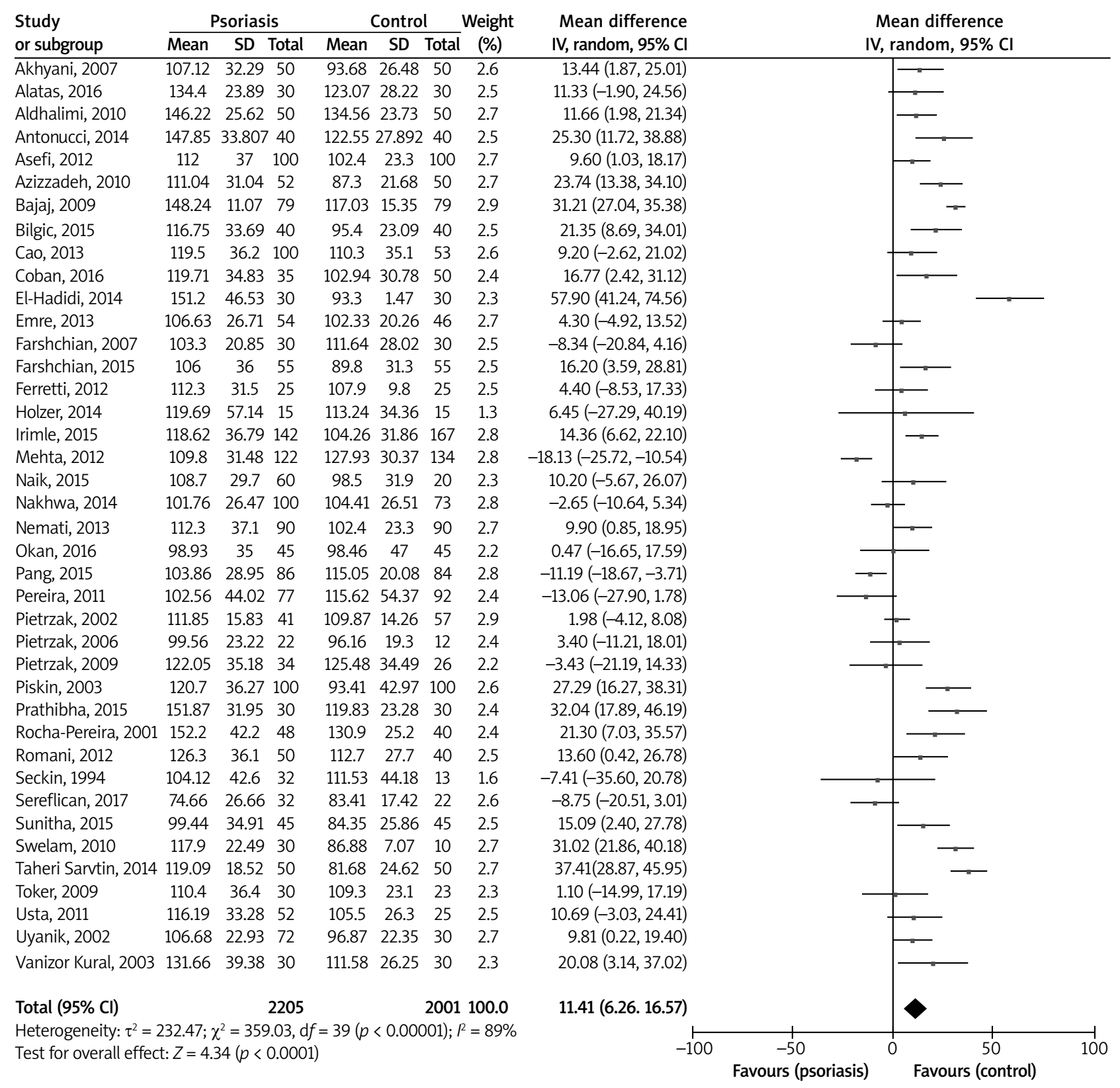

SD - standard deviation. *Study or subgroup shows "the first author's name and publication year".

Figure 4. Forest plot of random-effects model of serum low-density lipoprotein (LDL) levels in psoriatic patients compared with healthy controls

exist [33]. Cholesterol and LDL levels have been found to be higher in psoriasis, which could be related to the same pathogenesis of psoriasis and atherosclerosis [60]. Another factor that could contribute to the atherosclerotic process and subsequent CV events is represented by the increased carotid mean intima-media thickness (IMT); and this is of great importance in neurological diseases, since it plays a strong role in ischemic cerebrovascular events (strictly related to CV diseases) [61]. Increased IMT as well as a high prevalence of metabolic syndrome have been already reported in psoriatic patients [62-64].
Moreover, metabolic syndrome is closely linked to bad life habits leading to overweight/obesity and inactivity; in this regard, lifestyle factors such as smoking, alcohol consumption, sedentary lifestyle, and systemic psoriasis therapy may influence $C V$ risk factors and may have a negative direct impact on these risk factors $[26,39,47$, 49, 64, 65].

Epidemiological studies have demonstrated that smoking is not only a risk factor for psoriasis, but it also increases the severity of psoriasis while lowering the response to treatments [66]. Serum HDL levels were found 


\begin{tabular}{|c|c|c|c|c|c|c|c|c|c|c|c|}
\hline \multirow{2}{*}{$\begin{array}{l}\text { Study } \\
\text { or subgroup }\end{array}$} & \multicolumn{3}{|c|}{ Psoriasis } & \multicolumn{3}{|c|}{ Control } & \multirow{2}{*}{$\begin{array}{c}\text { Weight } \\
(\%)\end{array}$} & \multirow{2}{*}{$\begin{array}{l}\text { Mean difference } \\
\mathrm{IV} \text {, random, } 95 \% \mathrm{Cl}\end{array}$} & \multirow{2}{*}{\multicolumn{3}{|c|}{$\begin{array}{l}\text { Mean difference } \\
\text { IV, random, } 95 \% \mathrm{Cl}\end{array}$}} \\
\hline & Mean & SD & Total & Mean & SD & Total & & & & & \\
\hline Akhyani, 2007 & 27.94 & 11.21 & 50 & 23.17 & 9.45 & 50 & 2.3 & $4.77(0.71,8.83)$ & & $\leftarrow$ & \\
\hline Alatas, 2016 & 36.3 & 15.89 & 30 & 29.28 & 9.8 & 30 & 1.6 & $7.02(0.34,13.70)$ & & $=$ & \\
\hline Aldhalimi, 2010 & 34.52 & 12.35 & 50 & 27.91 & 11.67 & 50 & 2.1 & $6.61(1.90,11.32)$ & & - & \\
\hline Antonucci, 2014 & 31.63 & 10.67 & 40 & 28.044 & 9.83 & 40 & 2.2 & $3.59(-0.91,8.08)$ & & $=$ & \\
\hline Asefi, 2012 & 24.6 & 13.4 & 100 & 22.66 & 8.68 & 100 & 2.6 & $1.94(-1.19,5.07)$ & & + & \\
\hline Azizzadeh, 2010 & 28.13 & 8.92 & 52 & 20.2 & 7.46 & 50 & 2.6 & $7.93(4.74,11.12)$ & & - & \\
\hline Bajaj, 2009 & 37.81 & 10.78 & 79 & 36.68 & 7.87 & 79 & 2.6 & $1.13(-1.81,4.07)$ & & 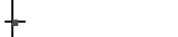 & \\
\hline Bilgic, 2015 & 21.65 & 14.93 & 40 & 17.87 & 7.34 & 40 & 2.0 & $3.78(-1.38,8.94)$ & & + & \\
\hline Cao, 2013 & 25.08 & 16.56 & 100 & 24.3 & 21.8 & 53 & 1.6 & $0.78(-5.93,7.49)$ & & - & \\
\hline Coban, 2016 & 26.966 & 512.49 & 35 & 27.348 & 27.46 & 50 & 1.2 & $-0.38(-9.05,8.28)$ & & - & \\
\hline El-Hadidi, 2014 & 31.29 & 20.26 & 530 & 14.07 & 2.63 & 30 & 1.4 & $17.22(9.91,24.53)$ & & $\because$ & \\
\hline Emre, 2013 & 26.51 & 15.2 & 54 & 21.17 & 10.41 & 46 & 2.0 & $5.34(0.29,10.39)$ & & - & \\
\hline Farshchian, 2007 & 24.32 & 10.91 & 30 & 25.4 & 13.7 & 30 & 1.7 & $-1.08(-7.35,5.19)$ & & $t$ & \\
\hline Farshchian, 2015 & 30.52 & 14.4 & 55 & 21.41 & 7 & 55 & 2.2 & $9.11(4.88,13.34)$ & & - & \\
\hline Ferretti, 2012 & 27.5 & 9 & 25 & 17.5 & 4.3 & 25 & 2.3 & $10.00(6.09,13.91)$ & & - & \\
\hline Girisha, 2017 & 31.6 & 8.3 & 156 & 26.1 & 7 & 156 & 3.0 & $5.50(3.80,7.20)$ & & $=$ & \\
\hline Holzer, 2014 & 27.7 & 17 & 15 & 25.9 & 17 & 15 & 0.7 & $1.80(-10.37,13.97)$ & & - & \\
\hline Irimle, 2015 & 32.6 & 11.3 & 142 & 21.9 & 9.1 & 167 & 2.8 & $10.70(8.39,13.01)$ & & - & \\
\hline Malelead, 2011 & 29.4 & 12 & 30 & 22.4 & 8.9 & 30 & 1.9 & $7.00(1.65,12.35)$ & & 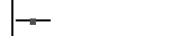 & \\
\hline Mehta, 2012 & 26.3 & 16.6 & 122 & 25.3 & 10.1 & 134 & 2.5 & $1.00(-2.41,4.41)$ & & - & \\
\hline Mysliwiec, 2017 & 22.5 & 10.4 & 85 & 22.7 & 10.5 & 32 & 2.2 & $-0.20(-4.46,4.06)$ & & $T$ & \\
\hline Naik, 2015 & 21.8 & 10.5 & 60 & 23.4 & 10.9 & 20 & 1.9 & $-1.60(-7.07,3.87)$ & & T & \\
\hline Nakhwa, 2014 & 42.97 & 19.52 & 93 & 28 & 11.47 & 73 & 2.1 & $14.97(10.21,19.73)$ & & $\pi$ & \\
\hline Nemati, 2013 & 24.5 & 13.6 & 90 & 25.6 & 13.7 & 90 & 2.3 & $-1.10(-5.09,2.89)$ & & + & \\
\hline Okan, 2016 & 23.81 & 18.5 & 45 & 19.48 & 19 & 45 & 1.3 & $4.33(-3.42,12.08)$ & & $t=$ & \\
\hline Pang, 2015 & 20.2 & 6.5 & 86 & 23.9 & 12.2 & 84 & 2.6 & $-3.70(-6.65,-0.75)$ & & & \\
\hline Pereira, 2011 & 26 & 12.3 & 77 & 28.2 & 16 & 92 & 2.2 & $-2.20(-6.47,2.07)$ & & of & \\
\hline Pietrzak, 2002 & 26.1 & 6.7 & 41 & 21.4 & 6.8 & 57 & 2.7 & $4.70(1.99,7.41)$ & & - & \\
\hline Pietrzak, 2006 & 22.39 & 7.58 & 22 & 15.12 & 6.99 & 12 & 2.0 & $7.27(2.20,12.34)$ & & $\rightarrow$ & \\
\hline Pietrzak, 2009 & 25.32 & 12.27 & 34 & 23.13 & 11.69 & 26 & 1.7 & $2.19(-3.91,8.29)$ & & 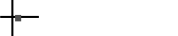 & \\
\hline Piskin, 2003 & 26.32 & 13.87 & 100 & 21.96 & 9.48 & 100 & 2.5 & $4.36(1.07,7.65)$ & & - & \\
\hline Prathibha, 2015 & 29.13 & 7.2 & 30 & 24.69 & 4.95 & 30 & 2.6 & $4.44(1.31,7.57)$ & & - & \\
\hline Praveenkumar, 2016 & 630 & 4.9 & 30 & 24.2 & 4.8 & 30 & 2.8 & $5.80(3.35,8.25)$ & & $=$ & \\
\hline Rocha-Pereira, 2001 & 124 & 9.9 & 48 & 18.6 & 6.3 & 40 & 2.5 & $5.40(1.99,8.81)$ & & - & \\
\hline Romani, 2012 & 25 & 14.4 & 50 & 21.6 & 15.8 & 40 & 1.7 & $3.40(-2.92,9.72)$ & & $f-$ & \\
\hline Seckin, 1994 & 34.8 & 14.1 & 32 & 40.2 & 39.7 & 13 & 0.3 & $-5.40(-27.53,16.73)$ & & 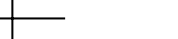 & \\
\hline Seishima, 1994 & 32 & 20 & 38 & 19 & 9.4 & 40 & 1.5 & $13.00(6.01,19.99)$ & & $\rightarrow$ & \\
\hline Sereflican, 2017 & 31.3 & 15.5 & 32 & 27.2 & 13.1 & 22 & 1.4 & $4.10(-3.57,11.77)$ & & - & \\
\hline Solak, 2017 & 27.5 & 13.2 & 70 & 27.7 & 18.6 & 60 & 1.8 & $-0.20(-5.83,5.43)$ & & + & \\
\hline Sunitha, 2015 & 25.11 & 9.23 & 45 & 23.16 & 4.99 & 45 & 2.6 & $1.95(-1.12,5.02)$ & & + & \\
\hline Swelam, 2010 & 39 & 5.7 & 30 & 28.8 & 3.3 & 10 & 2.7 & $10.20(7.31,13.09)$ & & - & \\
\hline Taheri Sarvtin, 2014 & 31.5 & 11.15 & 50 & 23.41 & 8.36 & 50 & 2.4 & $8.09(4.23,11.95)$ & & - & \\
\hline Takeda, 2001 & 20.8 & 7.3 & 27 & 16.2 & 5.6 & 15 & 2.3 & $4.60(0.65,8.55)$ & & - & \\
\hline Toker, 2009 & 23.3 & 12.8 & 30 & 29 & 19.6 & 23 & 1.1 & $-5.70(-14.93,3.53)$ & & & \\
\hline Uczniak, 2016 & 29.1 & 6 & 246 & 22.2 & 5.8 & 75 & 3.0 & $6.90(5.39,8.41)$ & & $=$ & \\
\hline Usta, 2011 & 27.7 & 13.3 & 52 & 17.7 & 10.2 & 25 & 1.9 & $10.00(4.61,15.39)$ & & $\rightarrow$ & \\
\hline Uyanik, 2002 & 30 & 5.2 & 72 & 23 & 4.4 & 30 & 2.9 & $7.00(5.02,8.98)$ & & - & \\
\hline Vanizor Kural, 2003 & 29.2 & 12.2 & 30 & 20.2 & 9.4 & 30 & 1.9 & $9.00(3.49,14.51)$ & & 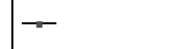 & \\
\hline Total $(95 \% \mathrm{Cl})$ & & & 2880 & & & 2439 & 100.0 & $4.82(3.63,6.00)$ & & 1 & \\
\hline $\begin{array}{l}\text { Heterogeneity: } \tau^{2}=1 \\
\text { Test for overall effec }\end{array}$ & $\begin{array}{l}\text { 11.57; } \\
\text { ct: } Z=\end{array}$ & $\begin{array}{l}x=-2 \\
7.98\end{array}$ & $\begin{array}{l}03.48, \\
p<0.0\end{array}$ & $\begin{array}{l}\mathrm{d} f=47 \\
0001)\end{array}$ & & 80 & & 100 & $\begin{array}{c}-50 \\
\text { Favours (psoriasis) }\end{array}$ & $\begin{array}{lr}0 & 50 \\
& \text { Favours (cor }\end{array}$ & ontrol) \\
\hline
\end{tabular}

$S D$ - standard deviation. *Study or subgroup shows "the first author's name and publication year".

Figure 5. Forest plot of random-effects model of serum very low-density lipoprotein (VLDL) levels in psoriatic patients compared with healthy controls

to be significantly lower in the smoker patients than in non-smoker controls; whereas, the serum TG levels were significantly higher. There was no compelling difference among the non-smoker patients, both control groups, and smoker patients regarding serum lipids, and PASI levels were significantly higher in smoker patients than in non-smoker patients, as previously reported by Emre et al. [22]. Therefore, HDL levels have protective proper- 


\begin{tabular}{|c|c|c|c|c|c|c|c|c|c|c|c|}
\hline \multirow{2}{*}{$\begin{array}{l}\text { Study } \\
\text { or subgroup }\end{array}$} & \multicolumn{3}{|c|}{ Psoriasis } & \multicolumn{3}{|c|}{ Control } & \multirow{2}{*}{$\begin{array}{l}\text { Weight } \\
\text { (\%) }\end{array}$} & \multirow{2}{*}{$\begin{array}{l}\text { Mean difference } \\
\mathrm{IV} \text {, random, } 95 \% \mathrm{Cl}\end{array}$} & \multirow{2}{*}{\multicolumn{3}{|c|}{$\begin{array}{c}\text { Mean difference } \\
\text { IV, random, } 95 \% \mathrm{Cl}\end{array}$}} \\
\hline & $\overline{\text { Mean }}$ & SD & Total & Mean & SD & Total & & & & & \\
\hline Akhyani, 2007 & 39.64 & 7.91 & 50 & 41.32 & 7.73 & 50 & 2.4 & $-1.68(-4.75,1.39)$ & & & \\
\hline Alatas, 2016 & 44.46 & 8.27 & 30 & 49.47 & 9.51 & 30 & 2.2 & $-5.01(-9.52,-0.50)$ & 7 & & \\
\hline Aldhalimi, 2010 & 39.62 & 3.76 & 50 & 43.88 & 3.52 & 50 & 2.6 & $-4.26(-5.69,-2.83)$ & $=$ & & \\
\hline Asefi, 2012 & 43.3 & 15 & 100 & 46.2 & 13.4 & 100 & 2.3 & $-2.90(-6.84,1.04)$ & & & \\
\hline Azizzadeh, 2010 & 44.67 & 6.99 & 52 & 43.86 & 7.83 & 50 & 2.4 & $0.81(-2.07,3.69)$ & & & \\
\hline Bajaj, 2009 & 39.75 & 11.3 & 79 & 42.2 & 10.49 & 79 & 2.4 & $-2.45(-5.85,0.95)$ & & & \\
\hline Bilgig, 2015 & 43.65 & 8.28 & 40 & 40.57 & 11.59 & 40 & 2.2 & $3.08(-1.33,7.49)$ & & - & \\
\hline Cao, 2013 & 51.1 & 14.7 & 100 & 55.3 & 13.3 & 53 & 2.2 & $-4.20(-8.80,0.40)$ & 7 & & \\
\hline Coban, 2016 & 48.48 & 10.81 & 35 & 47.92 & 14.1 & 50 & 2.1 & $0.56(-4.74,5.86)$ & & & \\
\hline El-Hadidi, 2014 & 30.87 & 6.8 & 30 & 51.8 & 4.75 & 30 & $2.4-$ & $-20.93(-23.90,-17.96)$ & - & & \\
\hline Emre, 2013 & 48.42 & 13.95 & 54 & 49.14 & 12.27 & 46 & 2.1 & $-0.72(-5.86,4.42)$ & & & \\
\hline Farshchian, 2007 & 37.3 & 4.96 & 30 & 35.5 & 4.17 & 30 & 2.5 & $1.80(-0.52,4.12)$ & & & \\
\hline Farshchian, 2015 & 66 & 10.4 & 55 & 49 & 9 & 55 & 2.4 & $17.00(13.37,20.63)$ & & - & \\
\hline Ferretti, 2012 & 51.3 & 16.6 & 25 & 52.9 & 6.9 & 25 & 1.8 & $-1.60(-8.65,5.45)$ & & & \\
\hline Girisha, 2017 & 44.42 & 9.02 & 156 & 46.53 & 7.7 & 156 & 2.5 & $-2.11(-3.97,-0.25)$ & & & \\
\hline Holzer, 2014 & 45.01 & 14.28 & 315 & 64.32 & 19.69 & 15 & 1.1 & $-19.31(-31.62,-7.00)$ & - & & \\
\hline Irimle, 2015 & 44.63 & 11.39 & 142 & 52.46 & 8.65 & 167 & 2.5 & $-7.83(-10.12,-5.54)$ & - & & \\
\hline Malelead, 2011 & 45.97 & 9.82 & 30 & 50.57 & 11.39 & 30 & 2.1 & $-4.60(-9.98,0.78)$ & - & & \\
\hline Mehta, 2012 & 45.66 & 16.29 & 122 & 51 & 14.81 & 134 & 2.3 & $-5.34(-9.17,-1.51)$ & & & \\
\hline Naik, 2015 & 54.5 & 16 & 60 & 54.6 & 18.5 & 20 & 1.5 & $-0.10(-9.16,8.96)$ & & & \\
\hline Nakhwa, 2014 & 43.01 & 7.94 & 100 & 37.47 & 12.18 & 73 & 2.4 & $5.54(2.34,8.74)$ & & - & \\
\hline Nemati, 2013 & 44.1 & 14.5 & 90 & 45.5 & 15.1 & 90 & 2.3 & $-1.40(-5.73,2.93)$ & & & \\
\hline Okan, 2016 & 42.9 & 14 & 45 & 37.2 & 11.25 & 45 & 2.1 & $5.70(0.45,10.95)$ & & - & \\
\hline Pang, 2015 & 43.24 & 9.27 & 86 & 50.96 & 9.27 & 84 & 2.5 & $-7.72(-10.51,-4.93)$ & - & & \\
\hline Pereira, 2011 & 53.29 & 15.9 & 77 & 48.76 & 12.85 & 92 & 2.2 & $4.53(0.11,8.95)$ & & - & \\
\hline Pietrzak, 2002 & 45.69 & 6.84 & 41 & 51.72 & 8.61 & 57 & 2.4 & $-6.03(-9.09,-2.97)$ & - & & \\
\hline Pietrzak, 2006 & 50.05 & 9.5 & 22 & 62.88 & 12.97 & 712 & 1.6 & $-12.83(-21.17,-4.49)$ & 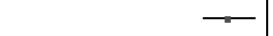 & & \\
\hline Pietrzak, 2009 & 48.16 & 8.71 & 34 & 56.77 & 12.38 & 326 & 2.1 & $-8.61(-14.20,-3.02)$ & $\rightarrow$ & & \\
\hline Piskin, 2003 & 47.3 & 10.68 & 3100 & 48.8 & 13.4 & 100 & 2.4 & $-1.50(-4.86,1.86)$ & & & \\
\hline $\begin{array}{l}\text { Prathibha, } 2015 \\
\text { Praveenkumar, } 2016\end{array}$ & $\begin{array}{l}31.39 \\
37.77\end{array}$ & $\begin{array}{l}6.917 \\
11.03\end{array}$ & $\begin{array}{l}30 \\
30\end{array}$ & $\begin{array}{l}45.03 \\
38.93\end{array}$ & $\begin{array}{c}5.22 \\
10.53\end{array}$ & $\begin{array}{l}30 \\
30\end{array}$ & $\begin{array}{l}2.4 \\
2.1\end{array}$ & $\begin{array}{r}-13.64(-16.74,-10.54) \\
-1.16(-6.62,4.30)\end{array}$ & $\rightarrow$ & & \\
\hline Rocha-Pereira, 2001 & 45.3 & 5.7 & 48 & 49.9 & 3.2 & 40 & 2.5 & $-4.60(-6.49,-2.71)$ & $=$ & & \\
\hline $\begin{array}{l}\text { Romani, } 2012 \\
\text { Seckin, } 1994\end{array}$ & $\begin{array}{c}51.1 \\
46.28\end{array}$ & $\begin{array}{c}11.6 \\
16.28\end{array}$ & $\begin{array}{l}50 \\
32\end{array}$ & $\begin{array}{l}55.7 \\
40.07\end{array}$ & $\begin{array}{l}16.4 \\
8.62\end{array}$ & $\begin{array}{l}40 \\
13\end{array}$ & $\begin{array}{l}2.0 \\
1.8\end{array}$ & $\begin{array}{r}-4.60(-10.61,1.41) \\
6.21(-1.12,13.54)\end{array}$ & $\rightarrow$ & & \\
\hline Seishima, 1994 & 41 & 15 & 38 & 48 & 6 & 40 & 2.1 & $-7.00(-12.12,-1.88)$ & $\rightarrow$ & & \\
\hline Sereflican, 2017 & 48.65 & 14.14 & 32 & 52.25 & 12.71 & 22 & 1.8 & $-3.60(-10.83,3.63)$ & - & & \\
\hline Solak, 2017 & 46.4 & 10.9 & 70 & 47.2 & 11.2 & 60 & 2.3 & $-0.80(-4.61,3.01)$ & & & \\
\hline Sunitha, 2015 & 35.82 & 5.92 & 45 & 37.82 & 7.12 & 45 & 2.5 & $-2.00(-4.71,0.71)$ & & & \\
\hline Swelam, 2010 & 63.666 & 4.9434 & 430 & 59.9 & 4.9 & 10 & 2.4 & $3.77(0.25,7.28)$ & & - & \\
\hline Taheri Sarvtin, 2014 & 47.6 & 8.82 & 50 & 53.8 & 6.64 & 50 & 2.4 & $-6.20(-9.26,-3.14)$ & - & & \\
\hline Toker, 2009 & $\begin{array}{r}38.5 \\
507\end{array}$ & 7.67 & 30 & 39.9 & 8.9 & 23 & 2.2 & $-1.40(-5.96,3.16)$ & & & \\
\hline Uczniak, 2016 & 58.74 & 14.56 & 5246 & 58.17 & 13.49 & 75 & 2.4 & $0.57(-2.98,4.12)$ & & & \\
\hline Usta, 2011 & 47.3 & 10.8 & 52 & 52.3 & 9.3 & 25 & 2.2 & $-5.00(-9.68,-0.32)$ & -1 & & \\
\hline Uyanik, 2002 & 37.91 & 10 & 72 & 41.96 & 8.22 & 30 & 2.3 & $-4.05(-7.79,-0.31)$ & -1 & & \\
\hline Vanizor Kural, 2003 & 45.56 & 6.95 & 30 & 52.12 & 10.81 & 30 & 2.2 & $-6.56(-11.16,-1.96)$ & $\rightarrow$ & & \\
\hline Total $(95 \% \mathrm{Cl})$ & & & 2735 & & & 2352 & 100.0 & $-2.78(-4.53,-1.03)$ & $\theta$ & & \\
\hline Heterogeneity: $\tau^{2}=3$ & $0.47 ; \chi$ & $=480$ & $.30, d$ & $f=4$ & 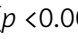 & 00001); & $=91 \%$ & & & & \\
\hline Test for overall effect & $\mathrm{t}: Z=3.1$ & $11(n-$ & $=0.002$ & & & & & -10 & $\begin{array}{cc}-50 & 0 \\
\text { Favours (psoriasis) }\end{array}$ & Favours $(\mathrm{c}$ & $\begin{array}{l}50 \\
\text { (control) }\end{array}$ \\
\hline
\end{tabular}

Figure 6. Forest plot of random-effects model of serum high-density lipoprotein (HDL) levels in psoriatic patients compared with healthy controls

ties against the CV risk [45]. Smoking increased the psoriasis risk nearly two folds [42]. Obesity is a known risk factor for psoriasis development and may be correlated with psoriasis activity. Psoriatic patients have a higher prevalence and incidence of obesity, and those with more severe skin lesions have higher odds of obesity than those with mild psoriasis [67].
In observational studies, it has also been reported that the risk of systolic hypertension was two times higher in psoriatic patients than in the general population, and more severe the development of psoriasis the higher the risk of hypertension [68]. On the other hand, it has to be taken in account that some antihypertensive drugs can play a role in inducing psoriasis, and, among them, $\beta$-blockers and 


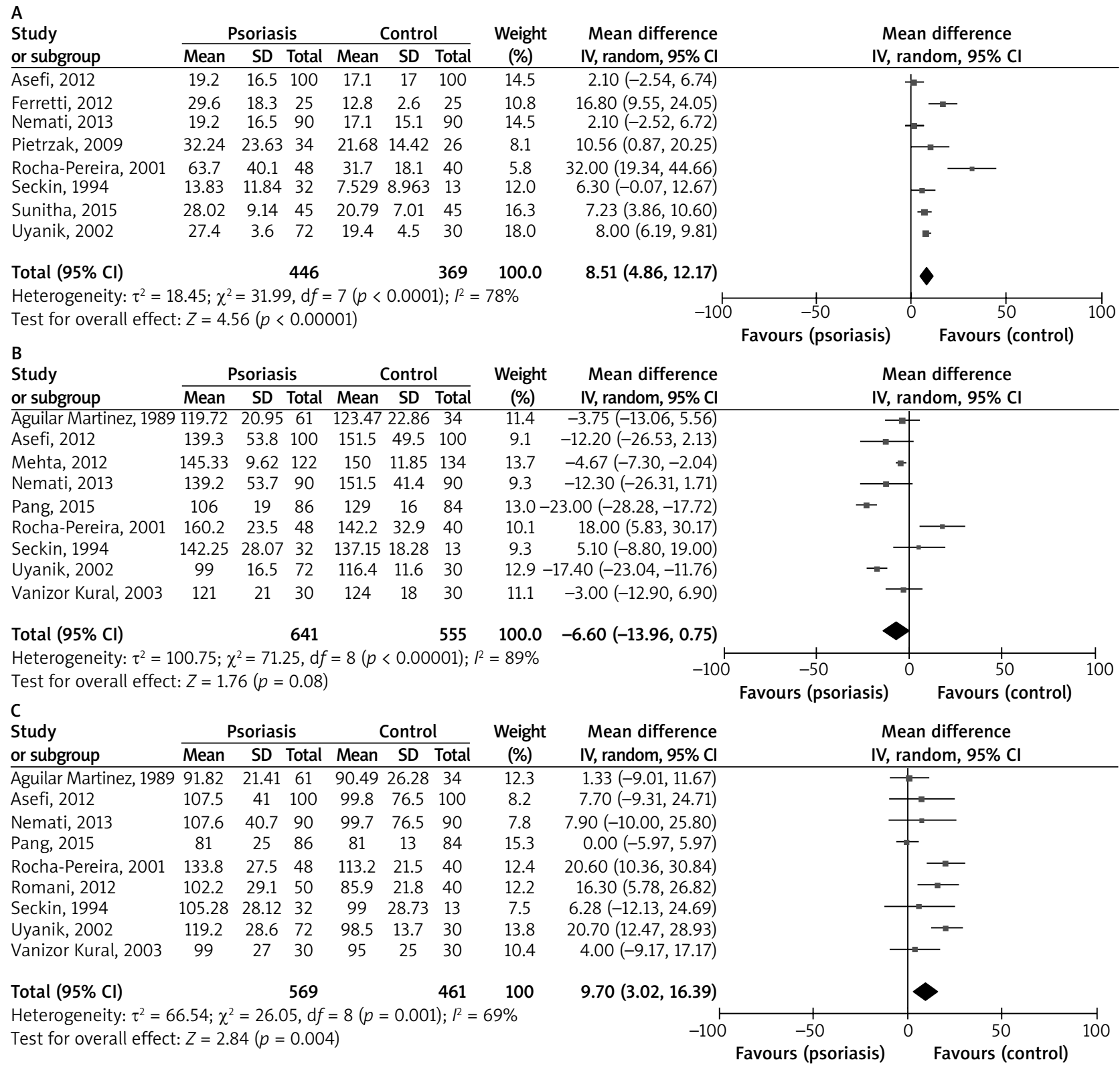

SD - standard deviation. *Study or subgroup shows "the first author's name and publication year".

Figure 7. Forest plot of random-effects model of serum lipoprotein (a) or Lp(a) (A), Apolipoprotein A1 (B), and Apolipoprotein $B(C)$ levels in psoriatic patients compared with healthy controls

sartans (i.e. losartan) are the most famous ones [69]. So, in case of patients suffering from hypertension, administration of certain category of drugs ( $\beta$-blockers, sartan molecules) might be avoided. This fact could probably represent a bias in some studies. It can be concluded that psoriasis may be an independent risk factor for diseases such as ischemic heart disease, DM, hypertension, and obesity [32].Conversely, long-term hypertensive status is associated with an increased risk of psoriasis $[46,68]$.

Increased Lp(a) levels and modifications of biochemical markers of lipid peroxidation related to the severity of psoriasis could be involved in the pathogenesis and progression of the disease and related complications [55]. Increased Lp(a) levels may also affect the expression of vascular adhesion protein 1 (VAP-1) or its activity in the adhesion and migration of $\mathrm{T}$ cells, thereby increasing the risk factor for psoriasis and its complications [11]. Therefore, lifestyle, eating habits, smoking and alcohol are important components that increase the incidence and severity of psoriasis. Also, some systemic diseases such as high blood pressure, DM, etc. can be other risk factors for this disease. Overall, lipid and lipoprotein changes in 
psoriatic patients, compared with healthy subjects, can be primary or secondary factors involved in the development of the disease, which should be considered in the first visit or during the patients' follow-up, thus even conditioning the choice of treatments.

There were several limitations in this meta-analysis. First of all, smoking and alcohol consumption had not been controlled in a lot of studies. Secondly, PASI score was different in the studies, although PASI score can easily change in the same patient during life (and not only in relation to treatment of psoriasis). Thirdly, in some studies the patients with psoriasis had metabolic syndrome, unless it is well-known that psoriasis is strictly associated to metabolic syndrome, thus leading to an increased risk of CV events (as stated above) [64]. Fourthly, there was a high heterogeneity among analyses. But the strengths of this study were: 1) age, sex, and BMI had been matched in the most studies; and 2) there was no bias in the analyses.

\section{Conclusions}

This extensive meta-analysis showed abnormality of serum lipid, lipoprotein, and apolipoprotein levels in psoriatic patients, compared with controls, and possibly a greater risk of atherosclerosis and CV accidents in the patients. Therefore, psoriatic patients should be risk-evaluated for CV accidents and atherosclerosis and should be carefully screened for lipid abnormalities, which can help in the early detection of lipid dysfunction and comorbidity of CV and atherosclerosis.

\section{Conflict of interest}

The authors declare no conflict of interest.

\section{References}

1. Irimie M, Oanță A, Irimie CA, et al. Cardiovascular risk factors in patients with chronic plaque psoriasis: a case-control study on the Brasov County population. Acta Dermatovenerol Croat 2015; 23: 28-35.

2. Romaní J, Caixàs A, Carrascosa JM, et al. Effect of narrowband ultraviolet B therapy on inflammatory markers and body fat composition in moderate to severe psoriasis. Br J Dermatol 2012; 166: 1237-44.

3. Nemati H, Khodarahmi R, Sadeghi M, et al. Antioxidant status in patients with psoriasis. Cell Biochem Funct 2014; 32: 268-73.

4. Puig-Sanz L Psoriasis, a systemic disease? Actas Dermosifiliogr 2007; 98: 396-402.

5. Myśliwiec H, Baran A, Harasim-Symbor E, et al. Serum fatty acid profile in psoriasis and its comorbidity. Arch Dermatol Res 2017; 309: 371-80

6. Krueger G, Ellis CN. Psoriasis recent advances in understanding its pathogenesis and treatment. J Am Acad Dermatol 2005; 53: S94-100.

7. Gelfand JM, Neimann AL, Shin DB. Risk of myocardial infarction in patients with psoriasis. JAMA 2006; 296: 1735-41.

8. Spuls PI, Lecluse LLA, Poulsen MNF, et al. How good are clinical severity and outcome measures for psoriasis: quan- titative evaluation in a systematic review. J Invest Dermatol 2010; 130: 933-43.

9. Deiana L, Pes GM, Carra C, et al. Lipid and lipoprotein profile in psoriasis. Boll Soc Hal Biol Sper 1992; 68: 755-9.

10. Aguilar Martinez A, Guerra Rodriguez P, Ambrojo Antunez P, et al. Serum levels of apolipoproteins Al, All and B in psoriasis. Dermatologica 1989; 179: 200-1.

11. Nemati H, Khodarahmi R, Rahmani A, et al. Serum lipid profile in psoriatic patients: correlation between vascular adhesion protein 1 and lipoprotein (a). Cell Biochem Funct 2013; 31: 36-40.

12. Moher D, Liberati A, Tetzlaff J, Altman DG; PRISMA Group. Preferred reporting items for systematic reviews and meta-analyses: the PRISMA statement. PLoS Med 2009; 6: e1000097.

13. Wells GA, Shea B, O'Connell D, et al. The Newcastle-Ottawa scale (NOS) for assessing the quality of non-randomised studies in meta-analyses. Ottawa: Ottawa Hospital Research Institute; 2011. Available at: http://www.ohri.ca/programs/clinical_epidemiology/oxford.asp. (last accessed 12 Jan 2016).

14. Hozo SP, Djulbegovic B, Hozo I. Estimating the mean and variance from the median, range, and the size of a sample. BMC Med Res Methodol 2005; 5: 13.

15. Biau DJ. In brief: Standard deviation and standard error. Clin Orthop Relat Res 2011; 469: 2661-4.

16. Seckin D, Tokgözoğlu L, Akkaya S. Are lipoprotein profile and lipoprotein (a) levels altered in men with psoriasis? J Am Acad Dermatol 1994; 31: 445-9.

17. Uyanik BS, Ari Z, Onur E, et al. Serum lipids and apolipoproteins in patients with psoriasis. Clin Chem Lab Med 2002; 40: 65-8.

18. Piskin S, Gurkok F, Ekuklu G, Senol M. Serum lipid levels in psoriasis. Yonsei Med J 2003; 44: 24-6.

19. Vanizor Kural B, Orem A, Cimşit G, et al. Plasma homocysteine and its relationships with atherothrombotic markers in psoriatic patients. Clin Chim Acta 2003; 332: 23-30.

20. Toker A, Kadi M, Yildirim AK, et al. Serum lipid profile paraoxonase and arylesterase activities in psoriasis. Cell Biochem Funct 2009; 27: 176-80.

21. Usta M, Turan E, Aral H, et al. Serum paraoxonase-1 activities and oxidative status in patients with plaque-type psoriasis with/without metabolic syndrome. J Clin Lab Anal 2011; 25: 289-95.

22. Emre S, Metin A, Demirseren DD, et al. The relationship between oxidative stress, smoking and the clinical severity of psoriasis. J Eur Acad Dermatol Venereol 2013; 27: e370-5.

23. Bilgiç R, Yıldız H, Abuaf OK, et al. Evaluation of serum asymmetric dimethylarginine levels in patients with psoriasis vulgaris. Arch Turk Dermatol Venerol 2015; 49: 13-8.

24. Alatas ET, Kalayci M, Kara A, Dogan G. Association between insulin resistance and serum and salivary irisin levels in patients with psoriasis vulgaris. Dermatologica Sinica 2017; 35: 12-5.

25. Coban M, Tasli L, Turgut S, et al. Association of adipokines, insulin resistance, hypertension and dyslipidemia in patients with psoriasis vulgaris. Ann Dermatol 2016; 28: 74-9.

26. Okan G, Baki AM, Yorulmaz E, et al. Serum visfatin, fetuin-A, and pentraxin 3 levels in patients with psoriasis and their relation to disease severity. J Clin Lab Anal 2016; 30: 284-9.

27. Sereflican B, Bugdayci G. Components of the alternative complement pathway in patients with psoriasis. Acta Dermatovenerol Alp Pannonica Adriat 2017; 26: 37-40.

28. Solak B, Dikicier BS, Erdem T. The role of uric acid in metabolic syndrome in patients with psoriasis. Turk Arch Dermatol Venereol 2017; 51: 37-40.

29. Farshchian M, Zamanian A, Farshchian M, et al. Serum lipid level in Iranian patients with psoriasis. J Eur Acad Dermatol Venereol 2007; 21: 802-5. 
30. Akhyani M, Ehsani AH, Robati RM, Robati AM. The lipid profile in psoriasis: a controlled study. J Eur Acad Dermatol Venereol 2007; 21: 1330-2.

31. Azizzadeh M, Ghorbani R, Sharafi M. Serum lipids profiles in psoriatic patients. J Semnan Univ Med Sci 2010; 11: 307-11.

32. Malekzad F, Robati $\mathrm{R}$, Abaei $\mathrm{H}$, et al. Insulin resistance in psoriasis: a case-control study. Iran J Dermatol 2011; 14: 136-9.

33. Asefi M, Vaisi-Raygani A, Bahrehmand F, et al. Paraoxonase 1 (PON1) 55 polymorphism, lipid profiles and psoriasis. Br J Dermatol 2012; 167: 1279-86.

34. Taheri Sarvtin M, Hedayati MT, Shokohi T, HajHeydari Z. Serum lipids and lipoproteins in patients with psoriasis. Arch Iran Med 2014; 17: 343-6.

35. Farshchian M, Ansar A, Sobhan M. Associations between cardiovascular risk factors and psoriasis in Iran. Clin Cosmet Investig Dermatol 2015; 8: 437-42.

36. Bajaj DR, Mahesar SM, Devrajani BR, Iqbal MP. Lipid profile in patients with psoriasis presenting at Liaquat University Hospital Hyderabad. J Pak Med Assoc 2009; 59: 512-5.

37. Pereira RR, Amladi ST, Varthakavi PK. A study of the prevalence of diabetes, insulin resistance, lipid abnormalities, and cardiovascular risk factors in patients with chronic plaque psoriasis. Indian J Dermatol 2011; 56: 520-6.

38. Nakhwa YC, Rashmi R, Basavaraj KH. Dyslipidemia in psoriasis: a case controlled study. Int Sch Res Notices 2014; 2014: 729157.

39. Prathibha K, Aliya Nusrath, Maithri CM. Assessment of inflammatory marker and dyslipidemias in psoriasis. Int J Pharm Sci Rev Res 2015; 31: 228-31.

40. Sunitha S, Rajappa M, Thappa DM, et al. Comprehensive lipid tetrad index, atherogenic index and lipid peroxidation: surrogate markers for increased cardiovascular risk in psoriasis. Indian J Dermatol Venereol Leprol 2015; 81: 464-71.

41. Praveenkumar U, Ganguly S, Ray L, et al. Prevalence of metabolic syndrome in psoriasis patients and its relation to disease duration: a hospital based case-control study. J Clin Diagn Res 2016; 10: WC01-5.

42. Girisha BS, Thomas N. Metabolic syndrome in psoriasis among urban South Indians: a case control study using SAM-NCEP criteria. J Clin Diagn Res 2017; 11: WC01-4.

43. Pietrzak A, Lecewicz-Toruń B. Activity of serum lipase [EC 3.1.1.3 and the diversity of serum lipid profile in psoriasis. Med $\mathrm{Sci}$ Monit 2002; 8: CR9-13.

44. Pietrzak A, Jastrzebska I, Krasowskaa D, et al. Serum pancreatic lipase [EC 3.1.1.3] activity, serum lipid profile and peripheral blood dendritic cell populations in normolipidemic males with psoriasis. J Mol Catal B Enzym 2006; 40: 144-54.

45. Pietrzak A, Kadzielewski J, Janowski K, et al. Lipoprotein (a) in patients with psoriasis: associations with lipid profiles and disease severity. Int J Dermatol 2009; 48: 379-87.

46. Uczniak S, Gerlicz ZA, Kozłowska M, Kaszuba A. Presence of selected metabolic syndrome components in patients with psoriasis vulgaris. Adv Dermatol Allergol 2016; 33: 114-9.

47. Mehta NN, Li R, Krishnamoorthy P, et al. Abnormal lipoprotein particles and cholesterol efflux capacity in patients with psoriasis. Atherosclerosis 2012; 224: 218-21.

48. Cao LY, Soler DC, Debanne SM, et al. Psoriasis and cardiovascular risk factors: increased serum myeloperoxidase and corresponding immunocellular overexpression by Cd11b(+) CD68(+) macrophages in skin lesions. Am J Transl Res 2013; 6: 16-27.

49. Naik HB, Natarajan B, Stansky E, et al. Severity of psoriasis as sociates with aortic vascular inflammation detected by FDG PET/CT and neutrophil activation in a prospective observational study. Arterioscler Thromb Vasc Biol 2015; 35: 2667-76.
50. Seishima M, Seishima M, Mori S, Noma A. Serum lipid and apolipoprotein levels in patients with psoriasis. Br J Dermatol 1994; 130: 738-42.

51. Takeda H, Okubo Y, Koga M, Aizawa K. Lipid analysis of peripheral blood monocytes in psoriatic patients using Fourier-transform infrared microspectroscopy. J Dermatol 2001; 28: 303-11.

52. Swelam MM, Ahmed MM, AllahAhmed NA, et al. The lipid profile in psoriatic patients. AAMJ 2010; 8: 284-91.

53. El-Hadidi H, Samir N, Shaker OG, Otb S. Estimation of tissue and serum lipocalin-2 in psoriasis vulgaris and its relation to metabolic syndrome. Arch Dermatol Res 2014; 306: 239-45.

54. Antonucci VA, Tengattini V, Balestri R, et al. Intima-media thickness in an Italian psoriatic population: correlation with lipidic serum levels, PASI and BMI. J Eur Acad Dermatol Venereol 2014; 28: 512-5.

55. Ferretti G, Bacchetti T, Campanati A, et al. Correlation between lipoprotein(a) and lipid peroxidation in psoriasis: role of the enzyme paraoxonase-1. Br J Dermatol 2012; 166: 204-7.

56. Holzer M, Wolf P, Inzinger M, et al. Anti-psoriatic therapy recovers high-density lipoprotein composition and function. J Invest Dermatol 2014; 134: 635-42.

57. Rocha-Pereira P, Santos-Silva A, Rebelo I, et al. Dislipidemia and oxidative stress in mild and in severe psoriasis as a risk for cardiovascular disease. Clin Chim Acta 2001; 303: 33-9.

58. Aldhalimi MA, Almuhanna SJ, Alrikabi SH. Serum lipid level in Iraqi patients with psoriasis. Skinmed 2010; 8: 204-6.

59. Pang X, Lin K, Liu W, et al. Characterization of the abnormal lipid profile in Chinese patients with psoriasis. Int J Clin Exp Pathol 2015; 8: 15280-4.

60. Frostegard J, Ulfgren AK, Nyberg P, et al. Cytokine expression in advanced human atherosclerotic plaques: dominance of proinflammatory (Th1) and macrophage stimulating cytokines. Atherosclerosis 1999; 145: 33-43.

61. Prati P, Vanuzzo D, Casaroli M, et al. Determinants of carotid plaque occurrence. A long-term prospective population study: the San Daniele Project. Cerebrovasc Dis 2006; 22: 416-22.

62. Troitzsch P, Paulista Markus MR, Dörr M, et al. Psoriasis is associated with increased intima-media thickness--the Study of Health in Pomerania (SHIP). Atherosclerosis 2012; 225: 486-90.

63. Kothiwala SK, Khanna N, Tandon N, et al. Prevalence of metabolic syndrome and cardiovascular changes in patients with chronic plaque psoriasis and their correlation with disease severity: a hospital-based cross-sectional study. Indian J Dermatol Venereol Leprol 2016; 82: 510-8.

64. Rodríguez-Zúńiga MJM, García-Perdomo HA. Systematic review and meta-analysis of the association between psoriasis and metabolic syndrome. J Am Acad Dermatol 2017; 77: 657-66.e8.

65. Naldi L, Chatenoud L, Linder D, et al. Cigarette smoking, body mass index, and stressful life events as risk factors for psoriasis: results from an Italian case-control study. J Invest Dermatol 2005; 125: 61-7.

66. Armstrong AW, Armstrong EJ, Fuller EN, et al. Smoking and pathogenesis of psoriasis: a review of oxidative, inflammatory and genetic mechanisms. Br J Dermatol 2011; 165: 1162-8.

67. Armstrong AW, Harskamp CT, Armstrong EJ. The association between psoriasis and obesity: a systematic review and metaanalysis of observational studies. Nutr Diabetes 2012; 2: e54.

68. Gottlieb AB, Dann F. Comorbidities in patients with psoriasis. Am J Med 2009; 122: 1150.e1-9.

69. Balak DM, Hajdarbegovic E. Drug-induced psoriasis: clinical perspectives. Psoriasis (Auckl) 2017; 7: 87-94. 